\title{
Burnout Status at Work among Health Care Professionals in aTertiary Hospital
}

\author{
Asrat Biksegn ${ }^{1,}$ Tesfay Kenfe ${ }^{2}$, Soboka Matiwos ${ }^{3}$, Girma Eshetu $^{4}$
}

\begin{abstract}
BACKGROUND: Burnout is a physical, physiological and psychological stress reaction syndrome Caused by long-term exposure to intense work-related emotional and interpersonal pressures. There is no evidence on the issue in Ethiopian setting.

METHODS: An institution based cross-sectional study design was conducted on 403 health care providers. Burnout was detected using Copenhagen's burnout inventory tool. Other structured questionnaire on work-related condition and substance use habits was used to collect data. Binary logistic regression was used to identify the associated factors of burnout at work.

RESULT: Of all the study participants, 36.7\% scored above the mean level of burnout. Highest prevalence $(82.8 \%)$ of burnout status was found among nurses. The least prevalence of burnout was observed among laboratory technicians which was $2.8 \%(n=4)$. Job insecurity, history of physical illness, low interest in profession, poor relationship status with managers, worry of contracting infection or illness and physical/verbal abuse were found to be predictors of burnout.

CONCLUSION: The prevalence of burnout at work was found to be high. The predictors were job insecurity, history of physical illness, low interest in profession, poor relationship status with managers, worry of contracting infection or illness and physical/verbal abuse.
\end{abstract}

KEYWORDS: Burnout, Health professionals, Occupational health, Work related factors

DOI: http://dx.doi.org/10.4314/ejhs.v26i2.3

\section{INTRODUCTION}

Burnout is a physical, physiological and psychological stress reaction syndrome resulting from long-term exposure to intense work-related emotional and interpersonal pressures $(1,2)$. Prolonged exposure to extreme levels of stress leads to health consequences. Burnout is the most frequent and imminent health problem with prevalence of $20 \%-60 \%$ among different professionals (3). Although the work of health professionals can be rewarding, factors such as work-life imbalance, long hours of work, perceived workload, concerns over complaints against health professionals and lack of reciprocity in relationships with patients and colleagues may reduce job satisfaction, and consequently can increase the risk of having high burnout (4).

\footnotetext{
${ }^{1}$ Department of Psychiatry Nursing, Aksum University, Ethiopia

${ }^{2}$ Department of Psychiatry Nursing, Mekelle University, Ethiopia

${ }^{3}$ Department of Psychiatry, Jimma University, Ethiopia

${ }^{4}$ Department of Preventive Medicine, Addis Ababa University, Ethiopia

Corresponding Author: Tesfay Kenfe, Email: kinfetesfay@gmail.com
}

Man studies found out the prevalence and incidence of burnout higher among health professionals. Few of the most predicting factors for burnout were long years of work experience, long hours of work per week- dealing with patients' psychological problems, disturbance of family life pertaining to work and substance use (5). According to different studies, the tendency towards substance abuse and suicide is due to serious consequence of burnout associated with access to pharmaceuticals and self-treatment of pain $(4,6)$.

A cross-sectional study conducted in Slovenia and Granada on health care workers showed high prevalence of burnout (43\%-50\%) in three dimensions. According to these studies, high 
burnout was significantly associated with working in emergency unit, night shift work and old age $(7,8)$. A similar study in Greek on health professionals found statically significant association by medical supply shortages with emotional exhaustion and depersonalization (9). A large scale South African study on health professionals working in Cape Town Metropolitan Municipality Community Healthcare Clinic and District Hospital of the Provincial identified long working hours, workload, work conditions and system related frustrations as the most important contributing factors of burnout syndrome (10).

On the other side, it is crucial to keep the wellbeing of health professionals to achieve quality patient care. Health professionals with burnout have lesser attention to their patients in providing routine care. As a result, they are very important agents in the prevention of nosocomial infections (hospital acquired infections) and in dealing with patient care and safety $(11,12)$.

A study on health professionals working with psychiatric patients indicated working more hours, having more patients with personality disorders, increased patient case loads, female gender, and being a psychiatrist were predictors of higher burnout scores. Similarly, having secured jobs, more clinical experience and being a psychologist predicted lower burnout scores (13). Another study in Malawi reported that burnout appears to be common among maternal health staff who experienced higher burnout scores than their colleagues working in other medical settings (14).

This study aimed to investigate the prevalence and predictor of burnout which is assumed to bring insight about its burden and severity in low socio-economic settings.

\section{MATERIALS AND METHODS}

The study was conducted among health care staff working at Jimma University Teaching Hospital (JUTH), Jimma Zone of the Oromiya Region, located in Southwest Ethiopia. The hospital is serving about 15 million people. Cross-sectional study design was used to assess the prevalence and risk factors of burnout among health care professionals working at JUTH. Self- administered questionnaire was distributed to all health professionals working at JUTH $(\mathrm{N}=403)$ from November 15, 2013 to December 15, 2013 by trained data collectors. Health professionals who were on grief in the last two month of data collection period and those who were providing free services for the hospital were excluded.

Burnout was detected by using Copenhagen's burnout inventory tool which was used and validated in different studies $(15,16$, 17, 18, 19). It included 19 items and three dimensions (personal, work and client burnout) about emotional and physical disturbances in terms of severity and frequency. It is found valid tool to assess burnout among professionals working in health care services. In this study, burnout is defined as thd mean and above the mean score of CBI score. The self-reporting questionnaire (SRQ-20) was used to detect mental distress. According to SRQ-20, it was said to be mental distress when total score is 6 and above out of twenty after it was recoded. This instrument was developed by WHO to screen mental distress in primary health care settings and community of low-income countries (20). Alcohol use disorder was assessed by using CAGE tool at score of 2 above "YES" answers through four questions. Collinearity was checked among SRQ-20, Copenhagen's burnout inventory tool, CAGE and the scales were mutually exclusive. It is a valid and reliable screening tool for detection of alcohol use problems and was used in different studies in Ethiopia. It consists of four simple questions focusing on multidimensional issues about alcohol use. Other structured questions were used to assess socio-demographic characteristics, health related conditions and substance use. The data in this study is part of another research done from jimma Speciallized Hosptal and published in the title of "Mental Distress and Associated Factors among Health Professionals Working in Tertiary Teaching Hospital, South West Ethiopia".

Abbreviations CBIS: Copenhagen's Burnout Inventory Scale, ETB: Ethiopian Birr, JUTH: Jimma University Teaching Hospital, SPSS: Statistical Package for Social Sciences, SRQ: Self Reporting Questionnaire.

Health professional: In this study 'health professionals' referres to all trained and certified 
professionals who had direct involvement in health care services. It included physicians, nurses, pharmacist/druggist, laboratory technicians/ technologists, physiotherapist, anesthetist, sanitarian, x-ray technician and others.

Data analysis: Data were coded, entered, cleaned and analyzed using SPSS version 16.0. Dependent and independent variables were entered into bivariate logistic regression one by one to detect association of independent variables with outcome variables. All variables associated with burnout at bivariate logistic regression were entered into multivariate logistic regression once to control potential confounders. Variables with p-value less than 0.05 in multivariate regression were considered to be independent predictors of burnout.

Ethical issue: Ethical clearance was obtained from Jimma University Ethical Committee.
Detailed information about the objective of the study was explained to all participants before questionnaire administration. Informed consent was obtained from each participant before the commencement of data collection and confidentiality of each participant was ensured.

\section{RESULTS}

Characteristics of participants: Among 403 permanently employed health professionals of JUTH, $83 \%(n=334)$ of them were participated in this study. The majority of the participants were males $(64.7 \%, n=213)$ and the mean age of the participants was $28.6 \pm 7.65$ years. The mean monthly salary of the study participants was 2119.9 ETHB (1USD 21.0 ETHB) with standard deviation of 772.09. And, the mean service year in the same institution was 4.57 with standard deviation of 6.61 .

Table 1: Socio-demographic characteristics of health professionals working in JUTH, December, 2013.

\begin{tabular}{|c|c|c|c|}
\hline \multicolumn{2}{|c|}{ Socio-demographic variables } & \multirow{2}{*}{$\begin{array}{l}\text { Number } \\
213\end{array}$} & \multirow{2}{*}{$\frac{\%}{64.7}$} \\
\hline Sex & Male & & \\
\hline \multirow{5}{*}{ Religion } & Female & 116 & 35.3 \\
\hline & Orthodox & 156 & 46.7 \\
\hline & Protestant & 108 & 32.3 \\
\hline & Islam & 63 & 18.9 \\
\hline & Others $^{1}$ & 7 & 2.1 \\
\hline \multirow[t]{5}{*}{ Ethnicity } & Oromo & 166 & 49.7 \\
\hline & Amhara & 92 & 27.5 \\
\hline & Tigre/wolayta/Guragie & 33 & 9.9 \\
\hline & Dawuro/keficho & 24 & 7.2 \\
\hline & Others $^{2}$ & 43 & 5.7 \\
\hline \multirow[t]{4}{*}{ Marital status } & Single & 167 & 50.2 \\
\hline & Married & 114 & 34.2 \\
\hline & In relationship & 39 & 11.7 \\
\hline & Divorced/widowed & 13 & 3.9 \\
\hline \multirow[t]{4}{*}{ Monthly salary (ETB) } & $\leq 1434$ & 85 & 25.4 \\
\hline & $1435-2190$ & 83 & 24.9 \\
\hline & $2191-2602$ & 102 & 30.5 \\
\hline & $\geq 2603$ & 64 & 19.2 \\
\hline \multirow[t]{5}{*}{ Profession } & Nurse & 237 & 71.8 \\
\hline & Pharmacist & 29 & 8.8 \\
\hline & Lab. technologist & 25 & 7.6 \\
\hline & Physician & 15 & 4.5 \\
\hline & Others $^{1}$ & 24 & 7.3 \\
\hline \multirow[t]{4}{*}{ Academic status } & Degree & 172 & 52.0 \\
\hline & Diploma & 138 & 41.7 \\
\hline & General practitioner & 11 & 3.3 \\
\hline & Others ${ }^{4}$ & 10 & 3.0 \\
\hline \multirow[t]{2}{*}{ Have children } & No & 223 & 66.8 \\
\hline & Yes & 111 & 33.2 \\
\hline
\end{tabular}

${ }^{1}$ Catholic, Jehovah and no religion, ${ }^{2}$ Yem, Harari, Siltie, ${ }^{3}$ Psychiatrist nurse, Physiotherapist, anesthetist nurse and sanitary environmentalist, ${ }^{4}$ Specialist and master degree 
Table 2: Bivariate logistic regression: Association of work related factors with burnout among health professionals working in JUTH, December, 2013(n=334).

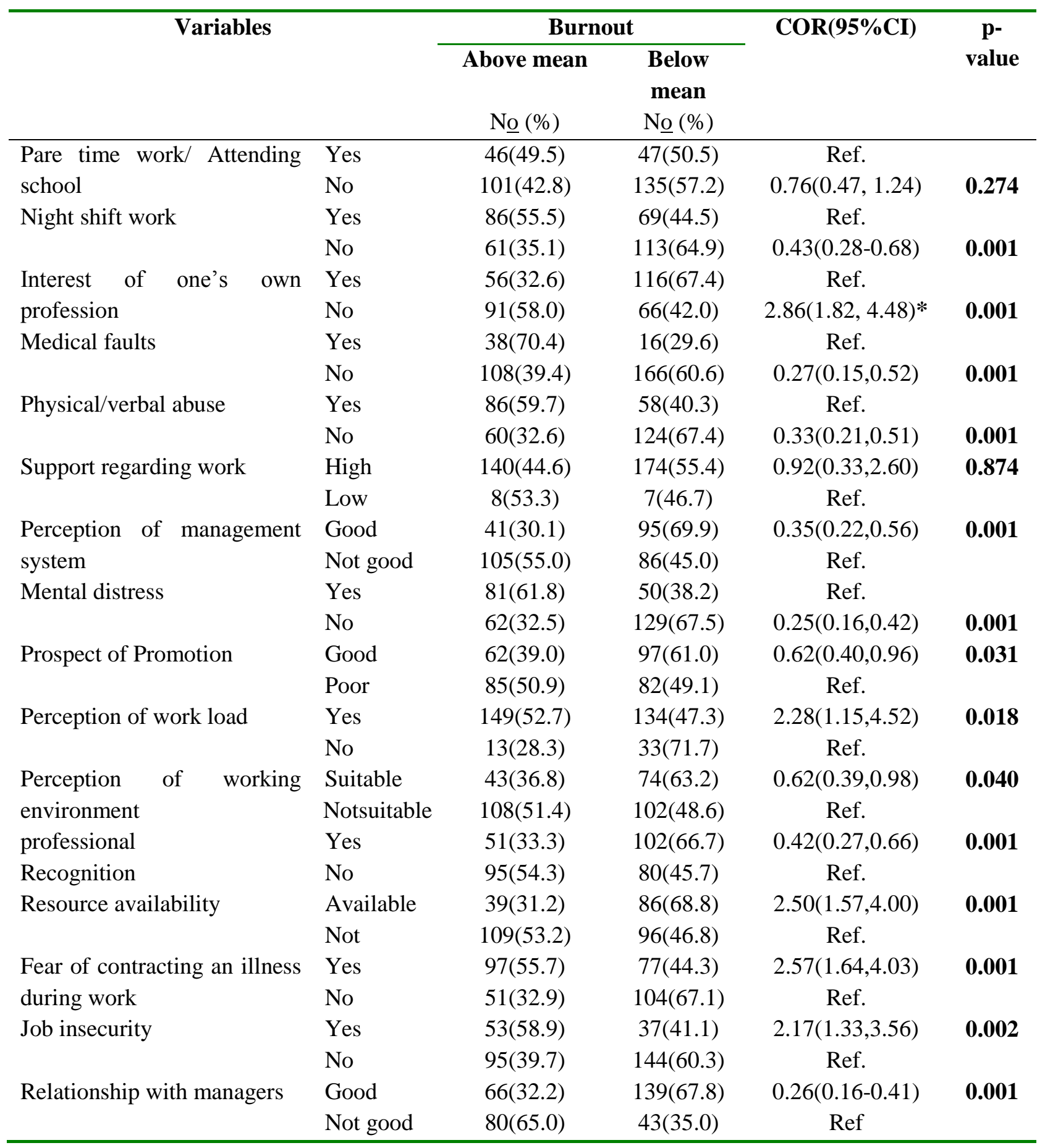

Half of the total participants were single in marital status $(50.2 \%)$ and $3.3 \%(\mathrm{n}=11)$ were divorced. The majority the participants $(52.0 \%$, $\mathrm{n}=172$ ) of were first degree holders (Table 1).
Prevalence of Burnout: Mean score of burnout was 50.27 with standard deviation of \pm 17.1528 . Among all the study participants, $36.7 \%$ showed that burnout above the mean. On the other hand, $64.4 \%(n=94)$ and $34.9(n=51)$ male and female 
participants scored above the mean respectively. Mentally distressed individuals had high, 56.6\% $(n=81)$, burnout score. Prevalence of burnout score was found to be high, $82.8 \% \quad(n=120)$, among nurses and the least prevalence of high burnout was observed among laboratory technicians which was $2.8 \%(n=4)$. Prevalence of burnout among participants reported as there is excessive workload4, 7.3\% $(\mathrm{n}=134)$, and $59.3 \% \quad(n=16)$ of health professionals with Alcohol Use Disorder scored above the mean.

The mean score of the three dimensions of burnout were: work burnout (mean score $=51.37, \mathrm{SD} \pm 19.07$ with $37.5 \%$ prevalence), client burnout (mean score $=51.02 \mathrm{SD} \pm 22.16$ with $37.2 \%$ prevalence) and personal burnout (mean score $=48.64 \mathrm{SD} \pm 19.97$ with $35.5 \%$ ).

Multivariate logistic regression: Variables identified to have statistically significant associations with burnout: After adjusting for potential confounders, using binary logistic regression analysis in which enter method (default) employed; it was found that status of job insecurity $(\mathrm{AOR}=0.37,95 \% \mathrm{CI}=0.15-0.92)$, physical illness $(\mathrm{AOR}=0.39,95 \% \quad \mathrm{CI}=0.15$ 0.98 ), interest to owns profession ( $\mathrm{AOR}=2.19$, $95 \% \mathrm{CI}=1.02-4.72)$, relationship with managers $(\mathrm{AOR}=0.39, \quad 95 \% \mathrm{CI}=0.16-0.98)$, worry of contracting infection or illness $(\mathrm{AOR}=3.06$, 95\% CI $=1.30-7.18)$ and Physical/Verbal abuse $(\mathrm{AOR}=0.36, \quad 95 \% \mathrm{CI}=0.17-0.77) \quad$ were significantly independently associated with high burnout.

The odds of developing burnout among participants who were not interested in their own profession was 2.19 times more than that of their counterparts. Additionally, the likelihood of developing high burnout among health professionals with worry of contracting infection or illness was 3.06 times higher than their peers who didn't perceive the worry of being infected. Health professionals who reported that their job was insecure were by $37 \%$ more likely to develop burnout. Similarly, participants with history of physical illness were by $39 \%$ at risk to have burnout (Table 3 ).

Table 3: Multivariate logistic regression: Variables identified to have statically significant associations with high burnout among health professionals working in JUTH, December, 2013 ( $n=334)$

\begin{tabular}{|c|c|c|c|c|c|}
\hline \multirow[t]{2}{*}{ Variables } & & \multicolumn{2}{|l|}{ Burnout } & \multicolumn{2}{|l|}{$\begin{array}{l}\text { Multiple logistic } \\
\text { regression }\end{array}$} \\
\hline & & $\begin{array}{l}\text { Above } \\
\text { mean } \\
\text { No }(\%)\end{array}$ & $\begin{array}{l}\text { Below } \\
\text { mean } \\
\text { No }(\%) \\
\end{array}$ & $\operatorname{AOR}(95 \% \mathrm{CI})$ & p-value \\
\hline $\begin{array}{l}\text { Perception of Job } \\
\text { insecurity }\end{array}$ & $\begin{array}{l}\text { Secured } \\
\text { Insecured }\end{array}$ & $\begin{array}{l}53(58.9) \\
95(39.7)\end{array}$ & $\begin{array}{l}37(41.1) \\
144(60.3)\end{array}$ & $\begin{array}{l}0.37(0.15-0.92) \\
\operatorname{Ref}\end{array}$ & 0.031 \\
\hline Physical illness & $\begin{array}{l}\text { Yes } \\
\text { No }\end{array}$ & $\begin{array}{l}43(63.2) \\
25(36.8)\end{array}$ & $\begin{array}{l}104(39.8) \\
157(60.2)\end{array}$ & $\begin{array}{l}0.39(0.15-0.98) \\
\text { Ref }\end{array}$ & 0.045 \\
\hline Interest to profession & $\begin{array}{l}\text { Interested } \\
\text { Not interested }\end{array}$ & $\begin{array}{l}56(32.6) \\
91(58.0)\end{array}$ & $\begin{array}{l}116(67.4) \\
66(42.0)\end{array}$ & $\begin{array}{l}\text { Ref } \\
2.19(1.02-4.72)\end{array}$ & 0.045 \\
\hline $\begin{array}{l}\text { Relationship with } \\
\text { managers }\end{array}$ & $\begin{array}{l}\text { Good } \\
\text { Not good }\end{array}$ & $\begin{array}{l}66(32.2) \\
80(65.0)\end{array}$ & $\begin{array}{l}139(67.8) \\
43(35.0)\end{array}$ & $\begin{array}{l}0.39(0.16-0.98) \\
\operatorname{Ref}\end{array}$ & 0.046 \\
\hline $\begin{array}{l}\text { Fear of contracting } \\
\text { infection }\end{array}$ & $\begin{array}{l}\text { Yes } \\
\text { No }\end{array}$ & $\begin{array}{l}97(55.7) \\
51(32.9)\end{array}$ & $\begin{array}{l}77(44.3) \\
104(67.1)\end{array}$ & $\begin{array}{l}3.06(1.30-7.18) \\
\text { Ref }\end{array}$ & 0.001 \\
\hline Physical/Verbal abuse & $\begin{array}{l}\text { Yes } \\
\text { No }\end{array}$ & $\begin{array}{l}86(59.7) \\
60(32.6)\end{array}$ & $\begin{array}{r}58(40.3) \\
124(67.4)\end{array}$ & $\begin{array}{l}\text { Ref } \\
0.36(0.17-0.77)\end{array}$ & 0.009 \\
\hline
\end{tabular}




\section{DISCUSSION}

The present study aimed to estimate the prevalence of burnout syndrome at work among health professionals and to analyze some of the work-related risk factors that can trigger burnout. The results showed high prevalence of burnout among health professionals. In general, our results coincide with similar studies conducted in USA, Spain and Brazil although the authors obtained large study participants with different measurement tool for burnout syndrome at work $(11,21,22)$. Thus, high burnout in health professionals has negative implications in hospital care services.

However, the finding of this study was relatively higher compared with previous similar studies carried out in different countries from 2010 to 2014 among health professionals $(2,6$, $12,23,24)$. It is possible that some of the aftermentioned difference might be due to increase in the level of stress whenever large number of patients allocated to each health professional. Responsibility for fewer patients may reduce the level of duty and stress at the same time. In other studies, presence of chronic stress is found to be positively associated with burnout at work $(2,25)$. The average age of the nurses in the above studies was above 40 years that underrepresents younger participants. Furthermore, $95 \%$ of the participants were females in the previous studies in that biological factors have great role for development of burnout $(9,26)$. However, too low prevalence of burnout was identified from other professional categories in 2011 in Brazil (27). In Brazilian, teachers indicated $12 \%$ prevalence of burnout which is far lower than the $36.7 \%$ prevalence in this stdy. The probable reason for the difference is that authors of the study cinducted in Brazilian utilized Spanish burnout inventory, educational version (SBI-Ed) tool to detect level of burnout which is different from our tool.

The $36.7 \%$ of burnout in this study prevalence is lower as compared with other findings such as; $51.5 \%$ in Greece, $50 \%$ in France, $69.2 \%$ in Spain and $45 \%$ in Iran among critical care health professionals $(9,26,28,29)$. Working in critical care increases the level of workload and stress. As a result, health personnel would experience burnout. Similarly, the study in Greece was conducted during economic crises in the state. Financial problems together with workload may also attribute to burnout at work as the study in Greece indicated. Moreover, the shortages medical supplay in Greece hospitals affected health care.

The second aim of our study was to determine whether or not there were any workrelated factors that were significantly associated with burnout status participants experienced. Factors appeared associated with burnout at final model were job insecurity, physical illness, lack if intereset in one's own profession, poor relationship with managers, fear of acquiring an infection and physical/verbal abuse from either staffs or patients.

Poor relationship with managers $(\mathrm{AOR}=0.39$, $\mathrm{CI}=0.16-0.98, \quad \mathrm{P}=0.046) \quad$ was positively associated with burnout. Health professionals with good relation with their bosses had $61 \%$ lesser risk for burnout compared with their counterparts. This result is consistent with the findings of previous studies conducted in Spain (2013) and France $(2007)(21,26)$. It infers that relationship status of the health care team strongly affects burnout status.

Similarly, history of physical illness (AOR=0.39, $\mathrm{CI}=0.15-0.98, \mathrm{P}=0.045$ ) was found to be a predictor of burnout among health professionals which is consistent with similar studies conducted in Brazil and India $(2,30)$. Poor general health affects all dimensions of life, and individuals with better general health condition can have good personal accomplishments sincethey are able to cope with different kinds of stressful conditions. Since our study is cross-sectional, it has limitations to identify causal relationship. In this case, if burnout comes first, then later people may be left susceptible to have physical illness because of poor functioning of immunity.

According to the findng of this study, physical/verbal abuse by patients and team mates $(\mathrm{AOR}=0.36, \mathrm{CI}=0.17-0.77, \mathrm{P}=0.009)$ was one of the risk factors contributing to burnout. This finding was in line with the findings of other similar studies carried out among international humanitarian health professionals in 2012 (25). Trauma had bad physical, psychological and social implications that left 
people to hate their work and finally unable to have occupational satisfaction.

Job security is the most important factor for employees especially in $3^{\text {rd }}$ world countries whenever there is no access to life insurance and low opportunities for jobs. Our study proved the above assumption that that staff who perceived as their job is insecure were by $37 \%$ at risk of having burnout $(\mathrm{AOR}=0.37,95 \% \mathrm{CI}=0.15-0.92$, $\mathrm{P}=0.031)$. It is consistent with the finding of a similar studies conducted Hong Kong $(\mathrm{P}=0.002)$ and in Yemen $(\mathrm{P}=0.011)$ on health professionals which identified poor job security as a predictor of burnout $(6,24)$. In conclusion, mean score of burnout was 50.27 with standard deviation of 17.1528. Among all study participants, $36.7 \%$ showed above the mean. The finding of this study was comparable with The findings of different studies. Probably, the most important findings of our study were the observed statically significant association of burnout with physical/verbal abuse, worry of confronting with illness and with lack of interest in one's own profession. Prevalence of high burnout was higher among nurses. Similarly, it was higher among health professionals with alcohol use disorder and mental distress. This study recommends prevention of stressful conditions, setting rules and regulations as well as strengthening staff communications to prevent harassment at work place. Similarly, health professionals need protection from any infectious illness of patients. Furthermore, training need to be given for all health professional who have direct contact with patients. High non-response rate and using different scales for comparison of burnout in discussion are limitations of the study.

\section{ACKNOWLEDGMENT}

This study was supported by Jimma University and JUTH. As stakeholder we would like to thank staffs of Jimma University and study participants. We would like to thank data collectors and department heads of JUTH for their welcome and assistance. Finally, we would like to acknowledge Jimma University, school of graduate studies for allowing us to conduct this study.

\section{REFERENCES}

1. Selic $\mathrm{P}$, Stegne-Ignjatovic $\mathrm{T}$, klemenc-ketis Z. Burnout among Family Medicine trainees. Original article, 2012; 81:218-224.

2. Ribeiro VF, Filho CF, Valenti VE and et al. Prevalence of burnout syndrome in clinical nurses at a hospital of excellence. International Archives of Medicine 2014,7(22).

http://www.intarchmed.com/content/7/1/22

3. Rudman A. Increase in study burnout during nursing education predicts lower levels of occupational preparedness and future clinical performance: A nationwide longitudinal study. The 2012 International Nursing Research Conference. Karolinska Institutet, Stockholm, Sweden.

4. Devalk M, and Oostrom C. Burnoutin the medical profession. Causes, consequences and solutions. Occupational Health at Work 2007; 3(6).

5. Gingras J, De jonge LA, and Purdy N. Prevalence of dietitian burnout. Journal of Human Nutrition and Dietetics. The British Dietetic Association Ltd. 2010J Hum Nutr Diet, 23, 238-243.

6. Christina FY Siu, Yuen SK, Cheung A. Burnout among public doctors in Hong Kong: cross-sectional survey. Hong Kong $\quad$ Med J, June 2012; 18:3.

7. Martínez OF, Cabrera CH, Tapia AM, and et al. Burnout among resident physicians who work duty shifts in the emergency department. emergencias2007;19:116-121.

8. Selic P, Stegne-Ignjatovic T, and klemencketis Z. Burnout among Slovenian family medicine trainees: A cross-sectional study. Zdrav Vestn, March 2012; 81.

9. Rachiotis G, Kourousis C, Kamilaraki M, and et al. Medical Supplies Shortages and Burnout among Greek Health Care Workers during Economic Crisis. International Journal of Medical Sciences 2014; 11(5):442-447.

10. Rossouw L, Seedat S, Emsley RA, and et al. The prevalence of burnout and depression in medical doctors. $S$ Afr Fam Pract 2013;55(6):567-573.

11. Gildasio S. de Oliveira Jr., Ray Chang., Paul C. Fitzgerald, and et al. The Prevalence of 
Burnout and Depression and Their Association with Adherence to Safety and Practice Standards: A Survey of United States Anesthesiology Trainees: Economics, Education, and Policy, July 2013; 117(1).

12. Cimiotti JP, Linda H, Douglas M, and et al. Nurse staffing, burnout, and health care associated infection. American Journal of Infection Control, 2012; 40: 486-90.

13. Kara K, Schmitz KJ, John CA, and et al. Predictors of Burnout Among Military Mental Health Providers. Military Medicine, March 2011; 176.

14. Thorsen VC, Tharp AL, and Meguid T. High rates of burnout among maternal health staff at a referral hospital in Malawi: A cross-sectional. BMC Nursing, 2011; 10:9.

15. Borritz M, and Kristensen TS. Copenhagen Burnout Inventory. First edition, February 2004.

16. Pejtersen JH, Kristensen TS, Borg V, et al. Second version of the Copenhagen Psychosocial Questionnaire. Scandinavian Journal of Public Health, 2010; 38(3): 8-24.

17. Ruiz EM, Gomez-Quintero HB, and Lluis SM. Validation of the Copenhagen Burnout Inventoryto Assess Professional Burnout in Spain. Rev Esp Salud Public 2013; 87:165179.

18. Campos JA, Carlotto MS, and Maroco J. Copenhagen Burnout Inventory Validation. Reflexao Critica, 2013; 26(1): 87-97.

19. Smit AM. Psychometric properties of the Copenhagens Burnout Inventory in South African context. University of Pretoria, September, 20.

20. World health organization division of mental health. User's Guideline to the Self Reporting Questionnaire. World Health Organization Geneva, 1994.

21. De la Fuente EI, Extremera RA, Pecino CV, and et al. Prevalence and risk factors of burnout syndrome among Spanish officers. Psicothema 2013; 25(4): 488-493.
22. Carlotto MS, Pizzinato A, Rocha KB, and et al. Prevalence and Factors Associated with Burnout Syndrome in Professionals in Basic Health Units. Ciencia \&Trabajo, May 2013; 15(47): 76-80.

23. Potter P, Deshields FT, J Divanbeigi J, and et al. Compassion Fatigue and Burnout: Prevalence Among Oncology Nurses. Clinical Journal of Oncology Nursing, October 2010; 14(5).

24. Al-Dubai SAR, and Rampal KG. Prevalence and Associated Factors of Burnout among Doctors in Yemen. Journal of Occupational Health, 2010;52:58-65.

25. Cardozo BL, Crawford CJ, Eriksson C, and et al. Psychological Distress, Depression, Anxiety, and Burnout among International Humanitarian Aid Workers: A Longitudinal Study. PLOS ONE, September 2012; 7(9).

26. Embriaco N, Papazian L, Kentish-Barnes N, and et al. Burnout syndrome among critical care healthcare workers. Current Opinion in Critical Care 2007, 13:482-488.

27. Gil-Monte PR, Carlotto MS, and Camara SG. Prevalence of burnout in a sample of Brazilian teachers. Eur. J. Psychiat. 2011; 25, (4): 205-212.

28. Siguero AM, García Perez MA, Gonzalez MA, and et al. Prevalence of Worker Burnout and Psychiatric Illness in Primary Care Physicians in a Health Care Area in Madrid. Aten Primaria 2003;31(9):564-74.

29. Ashtari Z, Farhady Y, and Khodaee MR Relationship between job burnout and work performance in a sample of Iranian mental health staff. AfrJPsychiatry, 2009;12:71-74.

30. Mohammadyfar MA, Khan MS, and Tamini BM. The Effect of Emotional Intelligence and Job Burnout on Mental and Physical Health. Journal of the Indian Academy of Applied Psychology, July 2009; 35(2): 219226. 